\title{
Livermore and UC labs join forces in mass spectroscopy
}

\section{Livermore, California}

LAWRENCE Livermore National Laboratory (LLNL) and the University of California (UC) have become research partners in an accelerator mass spectroscopy (AMS) facility to be part of LLNL's new Van der Graaf tandem accelerator. The collaboration, welcome to LLNL as a chance to improve relations with $\mathrm{UC}$ and diminish the laboratory's image as a bomb factory, was initiated by UC archaeologists who want to use AMS for highly sensitive carbon-dating, without having to wait in line for one of the 20 or so heavily subscribed AMS facilities elsewhere.

Such collaborative projects are likely to become more common under the new UC contract for management of the Lawrence Livermore, Los Alamos and Lawrence Berkeley national laboratories, signed last September. The contract calls for an increase in scientific collaboration between the laboratories and UC, funded in part by the management fees collected by the university.

For its contribution of $\$ 250,000$ - for construction of the AMS ion source and detector system - UC will be one of 5 partners in the accelerator, sharing the 4,000 hours of scheduled annual operating time equally with 3 LLNL departments and Sandia Laboratories in Albuquerque.
The sensitivity of AMS carbon dating derives from its ability to count every atom of an isotope, after accelerating up to 5 per cent of the atoms in the sample, and deflecting their paths based on atomic mass. The technique is up to 6 orders of magnitude more sensitive than traditional carbon dating based on radioactive decay.

LLNL scientists also plan to use AMS for composition analysis of proposed nuclear-waste disposal sites, as well as biomedical applications. AMS may also prove useful for nuclear weapons test diagnostics, but it is unlikely that the laboratory will do weapons experiments on the UC-funded beam line.

The AMS will be one of 19 beam lines and experiment stations of the new Van der Graaf tandem accelerator that will be used in a variety of research areas, including radioactive ion beams, nuclear spectroscopy and materials science. The entire facility cost $\$ 4$ million, a fraction of the potential price, thanks to innovative design, and bartering by Jay Davis, head of LLNL's nuclear physics division. It was built entirely from used parts, including the accelerator itself, acquired from the University of Washington, and the magnets for the AMS system, which were a gift from the Stanford Linear Accelerator Center.

\section{Note worth the plastic it's printed on}

\section{Sydney}

THE world's first banknote printed on clear plastic has been issued in Australia. The $\$ 10$ note includes anti-forgery devices designed to beat even the most sophisticated photographic copying. The print technology has been developed by Australia's Reserve Bank and the Commonwealth Scientific and Industrial Research Organisation (CSIRO) at a cost of A \$20 million.

The note has come up shining after immersion in beer, petrol, grease and tomato sauce, being put through a washing machine, boiled and buried for nine months. The plastic note has much the same thickness and feel as its paper predecessor, though perhaps a little greasier. The Reserve Bank is being cagey about the type of plastic used. The main breakthrough necessary to make the new note was getting the ink to adhere to the plastic substrate through thick and thin.

The note's main security feature is the eye-catching, almost gaudy, rainbowcoloured optically variable device (OVD), an aluminium diffraction grating image of Captain Cook, whose colours change with the angle of viewing. The layer of aluminium is so thin that it cannot be felt with the fingers. Another anti-photocopying device is the transparent window surrounding the OVD. Other innovations include micro-printing which is sharp on a scale smaller than easily seen with the naked eye.

In several South American countries notes are printed on a substrate of compressed plastic fibrils having much the same structure as paper, but none has ever been printed on clear plastic sheet before.

One side of the new note shows the HMS Supply, one of the First Fleet, and on the other side Aboriginal motifs including a boy wearing body paint, an ancient rock painting of a female figure, hand stencils and a ceremonial Morning Star Pole.

The commemorative note - issued in 1988 - to commemorate the 200th anniversary of European settlement in Australia, will be a test for the new technology. The new notes are more expensive to produce than their paper predecessors, but if they stand up to the rigours of use for longer than the average eight months of paper ten dollar notes then it won't be long until Australia's paper money is all plastic. The antiforgery technology should soon appear in other high security applications such as passports.

\section{SDI hails success in space test}

\section{Washington}

THE Strategic Defense Initiative Organization (SDIO) last week successfully orchestrated a $\$ 250$-million space mission to study detection and tracking of ballistic missiles.

SDIO described the mission, called Delta 181, as "one of the most complex unmanned Earth orbit space missions ever attempted by the United States". The National Aeronautics and Space Administration (NASA) on 8 February used a Delta rocket to launch the three-tonne payload into orbit for SDIO from the Kennedy Space Center at Cape Canaveral, Florida.

Tracking objects from space is a critical requirement for a ballistic missile defence. The Delta 181 payload carried passive sensors, including ultraviolet and infrared imagers and spectrometers, as well as active sensors such as a pulsed laser radar (lidar), a coherent Doppler lidar and a microwave radar.

Mission director Major Green said one instrument, an infrared imager, failed during the 12-hour data collection period, but other instruments would provide much of the same data.

The targets used in the exercise were 14 different test objects released by the Delta 181 once it had reached its orbit. SDIO is particularly interested in how well targets can be tracked against different backgrounds, as well as through the Earth's limb, just above the horizon.

Another experiment tracked boosting missiles to discriminate between the target and the hot gases from the rocket's engine, for which purpose the Delta 181 carried four targets with solid rocket motors. SDIO launched a three-stage Strype 11 sounding rocket from Hawaii that was tracked from orbit.

Approximately $10^{11}$ bits of data were collected by the Delta 181 mission, which is to be transmitted to ground stations over a ten-day period. Mission organizers will not explain why so much time is needed to transmit that much data, which could be handled by the Tracking and Data Relay System operated by the Goddard Space Flight Center in something like 20 minutes. Some have speculated that the extra time in space may be used to conduct experiments not yet announced, such as tracking other ground-launched targets.

Even critics of SDIO's plans to build a ballistic missile defence acknowledge that a mission such as Delta 181 is a necessary precursor to building a comprehensive system, but say that success does not prove that the concept of SDI is valid.

Joseph Palca 